\section{Early Mathematics}

门 is over ten years since my book Stamping through Mathematics (Springer 2001) was published, featuring around 400 mathematical stamps, enlarged and in full colour, with the stories that lie behind them. For the next few Stamp Corners I return to its pages, presenting some stamps that particularly appeal to me.

\section{Finger counting}

From earliest times people have counted and measured the objects around them. Early methods of counting included forming stones into piles, cutting notches in sticks, and finger counting, and it is surely through this last activity that our familiar decimal number system emerged.

\section{Stonehenge}

Geometrical alignments of stones have been found in many places. A celebrated example is the circular pattern of megaliths at Stonehenge. Although its exact purpose is unknown, it seems to have been designed to demonstrate astronomical events of religious significance, such as sunrise on midsummer's day.

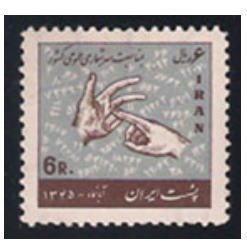

Finger counting

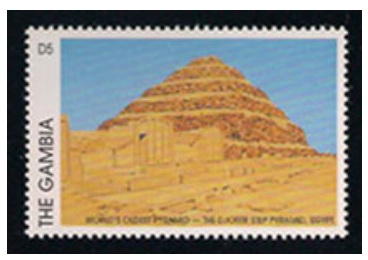

Step pyramid

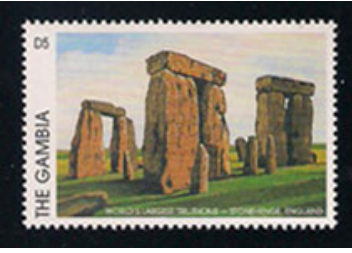

Stonehenge

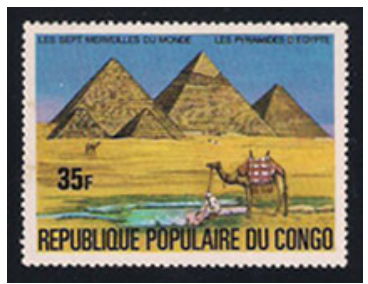

Pyramids of Giza

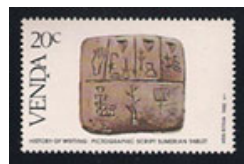

Sumerian tablet

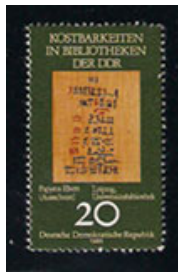

Egyptian papyrus

> Please send all submissions to the Stamp Corner Editor,

Robin Wilson, Pembroke College,

Oxford

OxIIDW, UK

e-mail: r.j.wilson@open.ac.uk

\section{Sumerian accounting tablet}

Early examples of mathematical writing appeared in Mesopotamia, between the rivers Tigris and Euphrates in presentday Iraq. This Sumerian tablet (c.3000 BC) features commodities such as barley; the three thumbnail indentations represent numbers. The Mesopotamian number system became a sexagesimal one (based on 60) which we still use in our measurement of time.

\section{Egyptian pyramids}

The oldest of the Egyptian pyramids, King Djoser's step pyramid (c.2700 BC) in Saqqara, was built in horizontal layers. Better known are the magnificent pyramids of Giza (c.2600 BC), which attest to the Egyptians' extremely accurate measuring ability: in particular, the Great Pyramid of Cheops has a square base whose sides of length 230-metre agree to less than $0.01 \%$. Constructed from more than two million blocks, this pyramid is 146 metres high and contains an intricate arrangement of internal chambers and passageways.

\section{Egyptian papyrus}

Our knowledge of later Egyptian science is scanty, since it was written on papyrus which was too fragile to survive the ravages of time. This stamp portrays a celebrated medical papyrus. In mathematics we have few primary sources, the main ones being the Moscow papyrus (c.1850 BC) and the Rhind papyrus (c.1650 BC): these include tables of fractions and many solved problems in arithmetic and geometry, probably designed for the teaching of scribes and accountants. 